\title{
Synthesis and Characterization of Starch Vernolates in Organic Solvents
}

\author{
Tegene Desalegn Zeleke ${ }^{1,}$, , Teshome Abdo Segne ${ }^{1}$, Yonas Chebude ${ }^{2}$ \\ ${ }^{1}$ Department of Chemistry, Adama Science and Technology University, Adama, Ethiopia \\ ${ }^{2}$ Department of Chemistry, Addis Ababa University, Addis Ababa, Ethiopia
}

Email address:

tegened@yahoo.com (T. D. Zeleke), teshomeab@yahoo.com (T. A. Segne), yonasdb1@yahoo.com (Y. Chebude)

${ }^{*}$ Corresponding author

\section{To cite this article:}

Tegene Desalegn Zeleke, Teshome Abdo Segne, Yonas Chebude. Synthesis and Characterization of Starch Vernolates in Organic Solvents. American Journal of Applied Chemistry. Vol. 4, No. 6, 2016, pp. 212-220. doi: 10.11648/j.ajac.20160406.11

Received: November 13, 2016; Accepted: November 25, 2016; Published: December 17, 2016

\begin{abstract}
In this study the synthesis of epoxy fatty acid esters of starch (starch vernolates) by the reaction of cassava starch with vernonia oil methyl ester (epoxy ester) using basic catalyst $\mathrm{K}_{2} \mathrm{CO}_{3}$ and organic solvent, DMSO as a reaction medium is presented. Under current reaction conditions, a high degree of substitution of 1.24 was achieved, at a reaction temperature of $110^{\circ} \mathrm{C}$ and 12 hours of reaction time. The new starch vernolates were characterized by Scanning electron microscopy (SEM) and X-ray diffraction (XRD) indicated that the new product is an amorphous material with a continuous and shapeless morphology. The melting point measured by differential scanning calorimetry (DSC) was $118^{\circ} \mathrm{C}$. The new synthetic method makes the synthesis of starch vernolates less time consuming and more inexpensive. The differences in melting point and degree of substitution with previously synthesized starch vernolates using enzymatic and chemical catalysis suggest a difference in reaction selectivity via this new reaction path.
\end{abstract}

Keywords: Vernonia Oil Methyl Ester, Cassava Starch, Starch Vernolates

\section{Introduction}

The challenges associated with the depletion of fossil oil resources and the huge environmental impact of petroleum based products are the major driving forces in searching for sustainable, renewable resources for both the provision of a vast inventory of organic molecules and indeed energy generation/storage vectors. The use of renewable raw materials in the chemicals industry for non-fuel applications offers enormous opportunity to establish a more sustainable development profile, enabling society to meet the needs of current and future generations whilst minimizing future environmental degradation [1]. Recently, plant oils and naturally occurring triglycerides of fatty acids, are being studied as potential sources of renewable feedstocks for the oleochemical industry [2]. Vernonia galamensis, a potentially novel industrial oilseed crop from the Asteraceae family was identified for the first time in Eastern part of Ethiopia by Perdue in 1964 [3]. The oil content of the seed of vernonia galamensis ranges from 35 to 40 weight $\%$. Vernonia oil is uniquely a naturally epoxidized seed oil with trivernolin contributing for about $60 \%$ of the triglycerides. The multiple chemical functionality of vernonia oil makes it a unique candidate for derivatization in order to synthesize high value-added products and synthetic intermediates [4]. The saponification of vernonia oil results in about $72-80 \%$ of naturally epoxidized fatty acid, vernolic acid (cis-12, 13-epoxy-cis-9octadecenoic acid) [5]. Recently, researchers have shown increasing interest in this species due to the presence of high content of vernolic acid in the seed oil. Vernolic acid offers potential application in the formulation of additives, coatings, and lubricant additives. Vernonia oil has become a unique renewable candidate for industrial feedstock due to its use as raw material and its potential derivatization into value-added products [1, 6-9].

Starch is one of the most widely used biopolymers because it is cheap, abundant and renewable [10]. However, the 
hydrophilic nature of starch has limited the scope of its application. Many industrial applications require the modification of native starches. Therefore, the modified starch derivatives could be obtained by either glucosidic bond cleavage (acid modification) or forming new functional groups (carbonyl group formation during oxidation), or substitution of free available hydroxyl groups (by etherification or esterification), or bridging of molecular chains by cross-linking reactions [10]. These modifications overcome the limitations of native starch properties [11]. Starch based materials may be used as potential substituent for petroleum-based plastic materials, particularly in the packaging industries [12].

Esterification is one of the most common methods of starch modification involving the hydroxyl groups. Starch fatty acid esters can be prepared either by chemical or enzymatic method. Synthesis of short chain fatty acid esters especially starch acetates from carboxylic acid $\left(\mathrm{C}_{1}-\mathrm{C}_{4}\right)$ were also reported elsewhere [13]. Furthermore, chemical methods of production of starch fatty acid esters by reacting starch with carboxylic acids $\left(\mathrm{C}_{4}-\mathrm{C}_{16}\right)$ are reported [14]. Junistia et al. reported the successful synthesis of long-chain fatty esters of corn starch with a broad range in degree of substitution (DS $=0.24-2.96$ ) by reacting the starch with fatty acid vinyl esters (e.g. vinyl laurate, vinyl stearate) in the presence of basic catalysts in DMSO [15]. Aburto et al. also reported that they prepared longer-chain fatty esters $\left(\mathrm{C}_{8}-\mathrm{C}_{18}\right)$ of potato starch and corn amylose using fatty acid chlorides and pyridine [16]. In another study, synthesis of starch fatty acid esters from fatty acid methyl esters (e.g. methyl palmitate, methyl laurate) as reactants and basic salts such as potassium carbonate, sodium acetate, sodium dihydrogen phosphate, and potassium methoxide at high temperatures and in polar aprotic solvents has been reported [17]. Polar solvents such as pyridine or DMSO are commonly used to dissolve starch to make the hydroxyl groups accessible towards esterification [18].

Our group have recently reported the synthesis of epoxy fatty acid esters of cassava starch by reacting cassava starch with vernonia oil methyl ester (epoxy ester) using 1-butyl-3-methylimidazolium hexafluorophosphate, $\left[\mathrm{C}_{4} \mathrm{C}_{1} \mathrm{Im}\right]\left[\mathrm{PF}_{6}\right]$ ionic liquid (IL) as a reaction medium and DMSO as co-solvent [1]. Similarly we have also reported the successful preparation of epoxy fatty acid esters of cassava starch (starch vernolates) by reacting cassava starch with vernonia oil methyl ester using only 1-butyl-3methylimidazolium chloride, $\left[\mathrm{C}_{4} \mathrm{C}_{1} \mathrm{im}\right] \mathrm{Cl}$, ionic liquid as a reaction medium and an inexpensive base such as pyridine as a catalyst [50].

The aim of this study was to synthesize and characterize a new starch ester containing the characteristic vernonia oil functionalities. The synthetic procedure used for the esterification of starch with vernonia oil methyl ester (VOME), derived from vernonia oil include the use of an organic solvent, DMSO, as reaction medium and basic $\mathrm{K}_{2} \mathrm{CO}_{3}$ as a catalyst.

\section{Materials and Methods}

\subsection{Materials}

Native cassava starch was procured from the local market in Addis Ababa, Ethiopia. The starch was dried for $24 \mathrm{~h}$ at $105^{\circ} \mathrm{C}$ in vacuo to ensure that the concentration of residual water was below $2 \%$, by weight, before use. Vernonia oil methyl ester (VOME) was prepared following literature procedures [19] using vernonia oil extracted from Vernonia galamensis seed, donated by Adet Agricultural Research Centre, Ethiopia. AnalaR grade DMSO was purchased from Sigma-Aldrich.

\subsection{Characterization Technique}

SEM micrographs were collected using a JEOL SEM Model LV 6400 microscope operating at $15 \mathrm{kV}$. The samples were coated with platinum in vacuo before analysis in order to make the samples conductive. Powder XRD patterns were acquired in a PANalytical $X$ 'Pert Pro with monochromatic $\mathrm{CuK} \alpha 1(\lambda=1.5406 \mathrm{~A}, 40 \mathrm{kV}, 40 \mathrm{~mA})$ radiation, in the angular range of $2^{\circ}-70^{\circ}(2 \theta)$. TGA analyses were performed using a Perkin Elmer TGA Q500 in a temperature range between 50 and $500^{\circ} \mathrm{C}$, with a heating rate of $10^{\circ} \mathrm{C} / \mathrm{min}$ and nitrogen gas flow of $50 \mathrm{ml} / \mathrm{min}$. DSC analyses were performed using a DSC Q2000. The samples (about $10 \mathrm{mg}$ ) were placed in sealed aluminum cups. After a first heating run from room temperature to $200^{\circ} \mathrm{C}$ to erase the thermal history of the material, each sample was cooled to $0^{\circ} \mathrm{C}$ and then heated again to $200^{\circ} \mathrm{C}$ (heating rate $10^{\circ} \mathrm{C} / \mathrm{min}$ ).

\subsection{Experimental Procedure}

Dried cassava starch $(1.0 \mathrm{~g}, 6 \mathrm{mmol}$, anhydroglucose unit, AGU) was first gelatinized in DMSO $(20 \mathrm{ml})$ at $70^{\circ} \mathrm{C}$ for $3 \mathrm{~h}$. To the transparent solution obtained, methyl vernolate ( $1 \mathrm{~mol} / \mathrm{mol}$ anhydroglucose units in starch, i.e., $1.91 \mathrm{~g}, 6 \mathrm{mmol})$ and $0.02 \mathrm{~g}(2 \% \mathrm{w} / \mathrm{w}$, with respect to starch) of potassium carbonate (catalyst) were added and the mixture was stirred at $110^{\circ} \mathrm{C}$ for $12 \mathrm{~h}$. After cooling, the product was precipitated under vigorous stirring using methanol $(100 \mathrm{~mL})$ and separated from the liquid phase by decantation. The product was further washed three times with methanol $(30 \mathrm{ml}$ and 15 $\mathrm{ml}, 10 \mathrm{ml}$ respectively). Finally, the product was dried in an oven $\left(60^{\circ} \mathrm{C}\right)$ and a brown solid product obtained was kept for characterization.

\subsection{The Determination of the Degree of Substitution (DS)}

The degree of substitution was determined using titrimetric method. The principle of the method is that if modified starch is saponified with a known amount of hot aqueous $\mathrm{NaOH}$, the ester bonds will be hydrolyzed and sodium acylates will form. When this solution is backtitrated with a standard strong acid (e.g. $\mathrm{HCl})$, the amount of $\mathrm{NaOH}$ used for saponification, can be calculated and consequently the acyl group substitution can be quantified. In this particular case, the DS of starch vernolate was determined using reported method [21] with minor 
modification. Approximately $0.5 \mathrm{~g}$ of dry starch vernolate was weighed and added into a $50 \mathrm{~mL}$ conical flask. Then 3 $\mathrm{mL}$ water and $5 \mathrm{~mL}$ of $1.0 \mathrm{M} \mathrm{NaOH}$ was added, and the conical flask was agitated with a magnetic stirrer at room temperature for $48 \mathrm{~h}$. After the indicator (phenolphthalein) was added, the excess alkali was titrated with $0.5 \mathrm{M}$ hydrochloric acid. The starch reference sample and duplicates were treated in a similar way.

The vernolyl content $(A \%)$ was calculated according to the following equation:

$$
A \%=\frac{\left[\left(V_{o}-V_{n}\right) \times \text { Molarityof } H C l \times M_{\text {vernoly } y} \times 10^{-3} \times 100\right.}{M}
$$

Where $V_{0}$ in $\mathrm{mL}$ is the volume of $0.5 \mathrm{~N} \mathrm{HCl}$ used to titrate the blank; $V n$ in $\mathrm{ml}$ is the volume of $0.5 \mathrm{~N} \mathrm{HCl}$ used to titrate the samples; $N$ is the concentration of the used $\mathrm{HCl}(\mathrm{mol} / \mathrm{L})$; $M$ in $g$ is the amount of dry starch vernolate sample; 279 is the formula weight of vernolyl groups. The vernolyl content
$(A \%)$ was used to calculate the degree of substitution, DS, according to the following equation:

$$
D S=\frac{(162 \times A \%)}{\left(M_{\text {vernolyl }} \times 100\right)-\left(\left(M_{\text {Vernolyl }}-1\right) \times A \%\right)}
$$

Where 162 is the molecular weight of glucose units and 279 is the formula weight of vernolyl group.

\section{Results and Discussion}

In this study, novel starch vernolate (epoxy starch fatty acid ester) was successfully prepared by esterification of endemic cassava starch with long chain epoxy fatty acid methyl ester i.e., vernonia oil methyl ester (VOME) in the presence of basic catalyst, potassium carbonate $\left(\mathrm{K}_{2} \mathrm{CO}_{3}\right)$ in DMSO as a solvent.

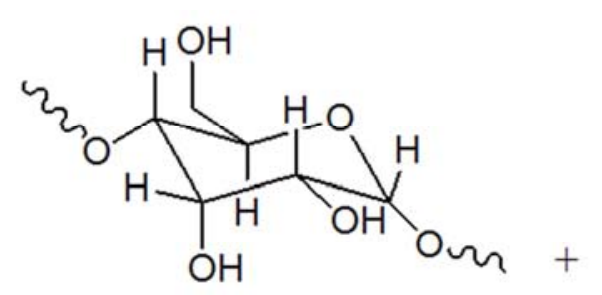<smiles>CCCCC[C@@H]1O[C@@H]1CC=CCCCCCCCC(=O)OC</smiles>

Methyl vernolate

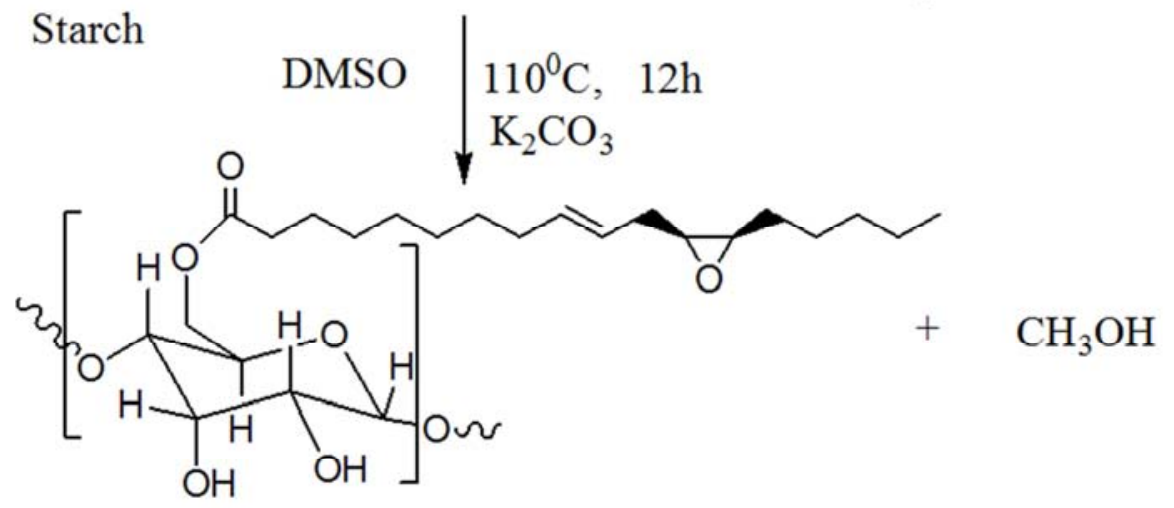

\section{Starch vernolate}

Figure 1. Schematic representation esterification of cassava starch with VOME.

\subsection{Solubility Studies}

Table 1. Solubility of starch, methyl vernolate and starch veronlate.

\begin{tabular}{llll}
\hline Solvent & Starch & Methyl vernolate & Starch vernolate \\
\hline Water & + & - & - \\
Methanol & $+/-$ & + & - \\
Ethanol & $+/-$ & + & - \\
Chloroform & - & + & - \\
\hline
\end{tabular}

$"+=$ soluble,$+/-=$ partially soluble and $-=$ insoluble"

The starch vernolate product was subjected to different solubility studies. Table 1 show that the starch vernolate is insoluble in all tested solvents in which the starting materials are soluble or partially soluble. The product and the starting materials exhibited different solubility trends which confirm that a new product has been synthesized. The insolubility of the product indicates that the new material is water proof and also resistant to many different organic solvents $[1,50]$.

\subsection{Thermal Analysis}

Differential Scanning Calorimetric (DSC) Analysis

The melting temperatures (Tm) of the native and starch vernolates were determined by differential scanning calorimetry studies. The $T m$ of native cassava starch in this study having about $10-13 \%$ moisture was $139^{\circ} \mathrm{C}$ as shown in Figure 1 below. It has been reported elsewhere that the Tm of cassava starch with $8-10 \%$ moisture content was found to be $162^{\circ} \mathrm{C}[28,29]$. Reports from separate study 
indicated that the glass transition temperature of native cassava starch which was $139^{\circ} \mathrm{C}$ has decreased during solution state enzymatic esterification with recovered coconut oil [18].

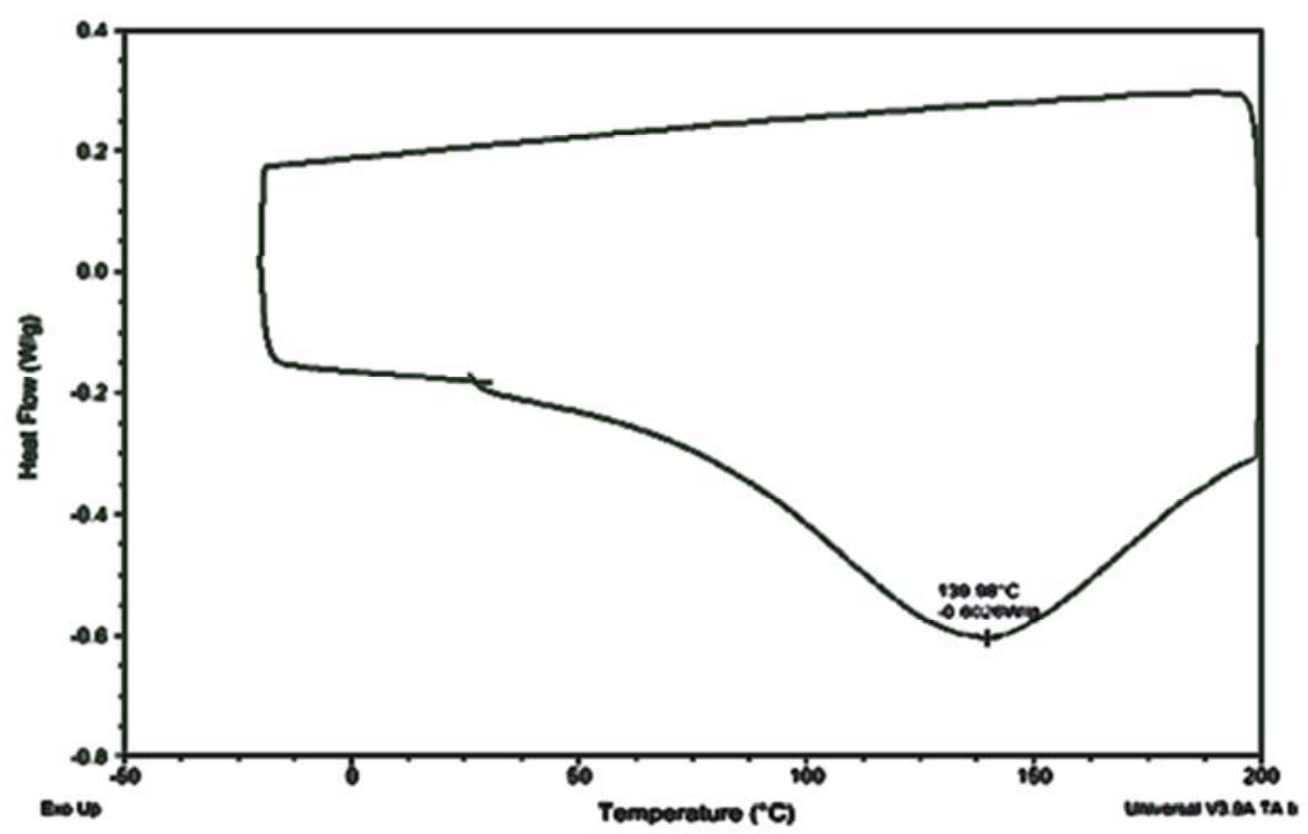

Figure 2. DSC thermogram of cassava starch.

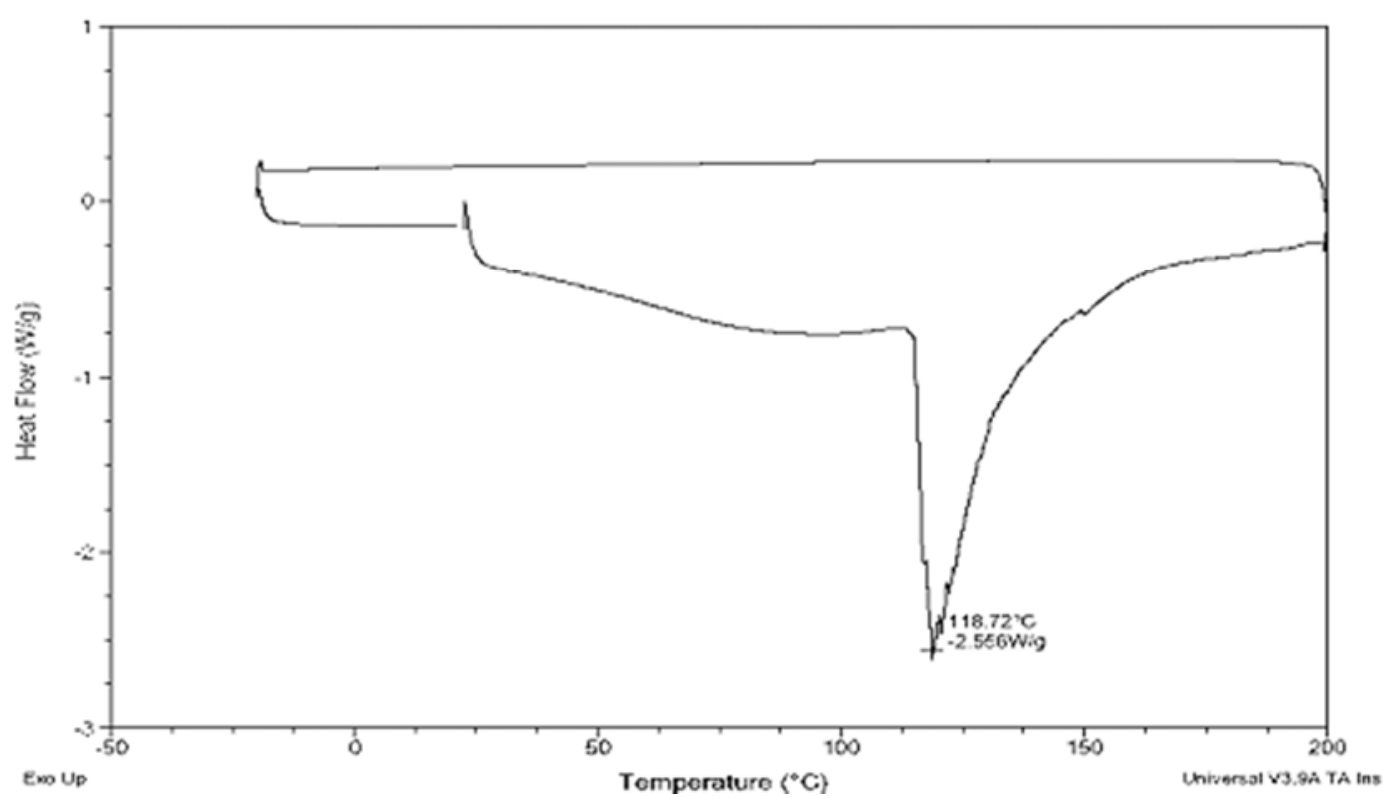

Figure 3. DSC thermogram of Starch vernolate.

DSC has been extensively used to study the Tm (melting point) on starch granules and $T g$ (glass transition temperature) on amorphous materials. $T \mathrm{~g}$ and $\mathrm{Tm}$ of the native starch were changed by the esterification reaction [30]. In Figures 2 and 3 above, it is shown that $T \mathrm{~m}$ of the native starch was $139^{\circ} \mathrm{C}$ and that of the starch vernolate was $118^{\circ} \mathrm{C}$, respectively. In other words, $T m$ of the modified starch is lower by $21^{\circ} \mathrm{C}$ than its unmodified counterpart. $\mathrm{Tm}$ of starch decreased with the increasing degree of esterification. This also agrees with the results reported elsewhere $[18,31]$. These changes can be explained by the fact that the intermolecular hydrogen bonds, which stiffen the macromolecular chain, decrease with the partial replacement of hydroxyl groups by vernolyl groups. Moreover, the increase in the free volume within the molecules due to the introduction of bulk groups that facilitates more molecular mobility also contributes to the decrease in $T \mathrm{~m}$ of starch after esterification $[18,32]$.

Thermogravimetric Analysis (TGA)

The thermal stability of native cassava starch and esterified cassava starch has been investigated by using TGA. The TG profiles were used to determine the weight loss of native cassava starch and starch vernolate as they were heated, 
cooled or held isothermally [26]. The initial weight loss in the starch started at lower temperature around $70-100^{\circ} \mathrm{C}$ corresponding to loss of water absorbed as natural starch is hydrophilic and can absorb moisture under normal room conditions. The other major degradation (i.e., more than $85 \%$ ) of native starch began at $306.5^{\circ} \mathrm{C}$ (Figure 4).

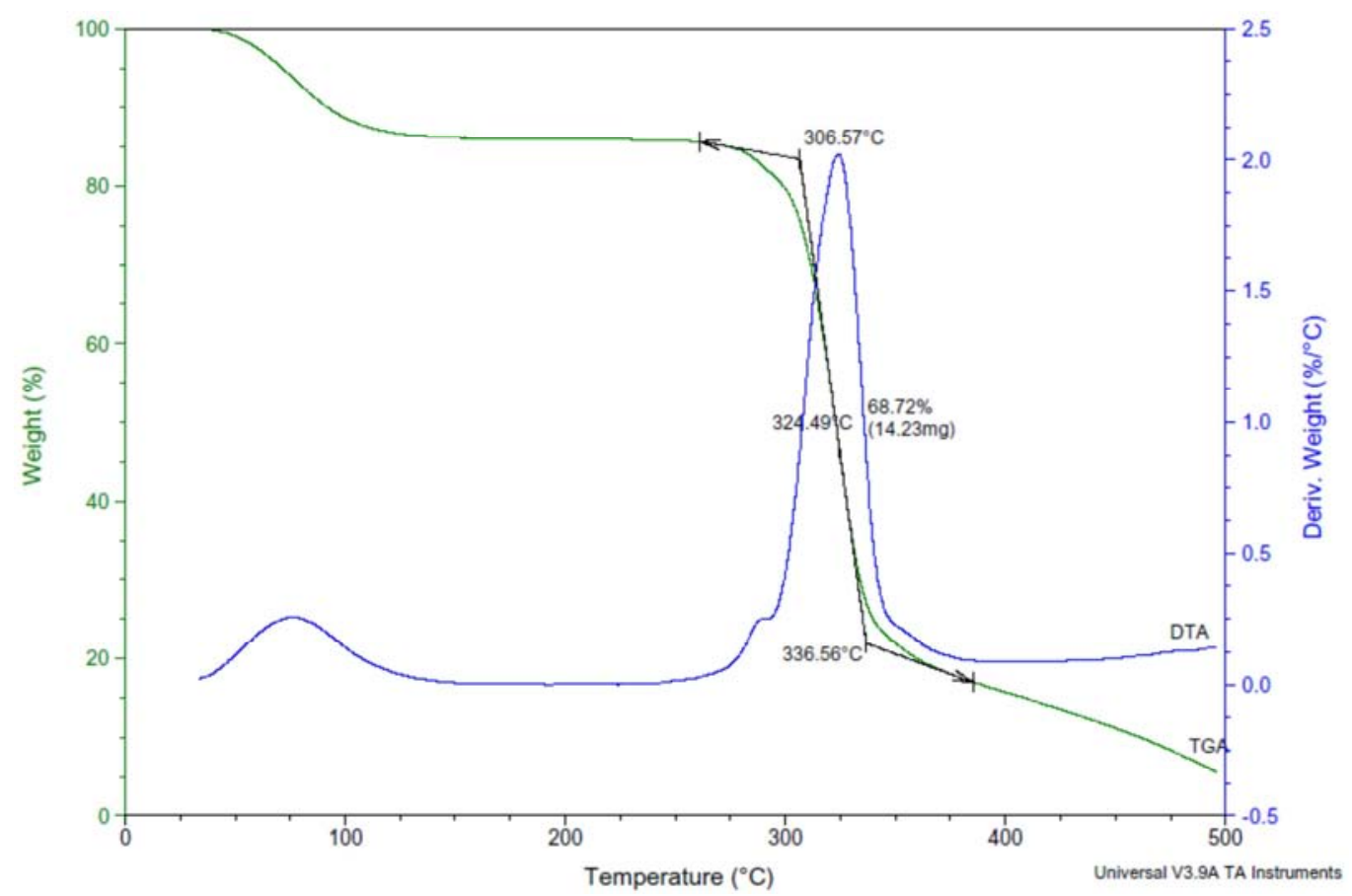

Figure 4. TGA thermogram of Cassava starch.

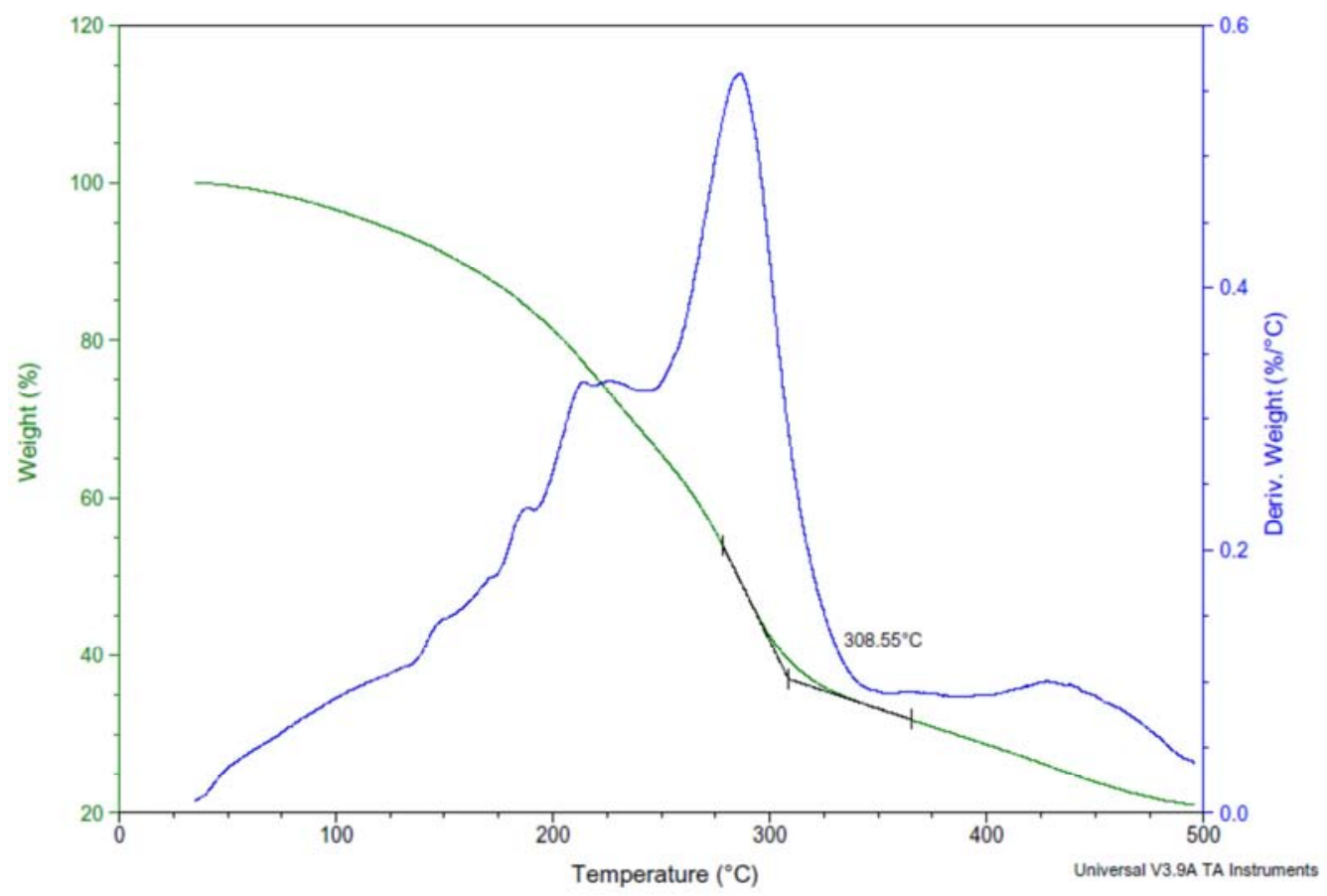

Figure 5. TGA thermogram of starch vernolate.

Although the initial of degradation of starch vernolate (Figure 4) started at lower temperature, it leaves more residues, i.e. $27 \%$ at $420^{\circ} \mathrm{C}$, which is more than cassava starch with a residue of only $13 \%$ at $420^{\circ} \mathrm{C}$. This is an indication of an overall higher thermal stability for starch vernolate $[33,34]$. The thermogram also shows difference in degradation products between the starch and starch vernolate, which could be another signal for the modification of starch i.e., esterification.

The improved thermal stability of starch esters as compared to native starch is probably due to the low content of hydroxyl groups in the former. Accordingly, the relatively higher degree 
of substitution achieved in this method of synthesis could have improved the thermal stability of the esterified starch. From TGA analysis, it can be concluded that esterified starch is thermally more stable than native starch.

\subsection{Structural Studies}

\section{Scanning Electron microscopy (SEM)}

In this study, the SEM images obtained show that there is a remarkable difference in appearance between native cassava starch (Figure 6) and starch vernolates (Figure 7) prepared by this method. Native cassava starch granules had spherical and truncated hemi-spherical shape $[35,36]$. However, the cassava starch granules which were spherical and truncated hemi-spherical ones have lost their individuality and smooth surface texture after esterification due of replacement of hydroxyl groups. The entire loss of granular nature of the starch confirms relatively high degree of substitution [35].

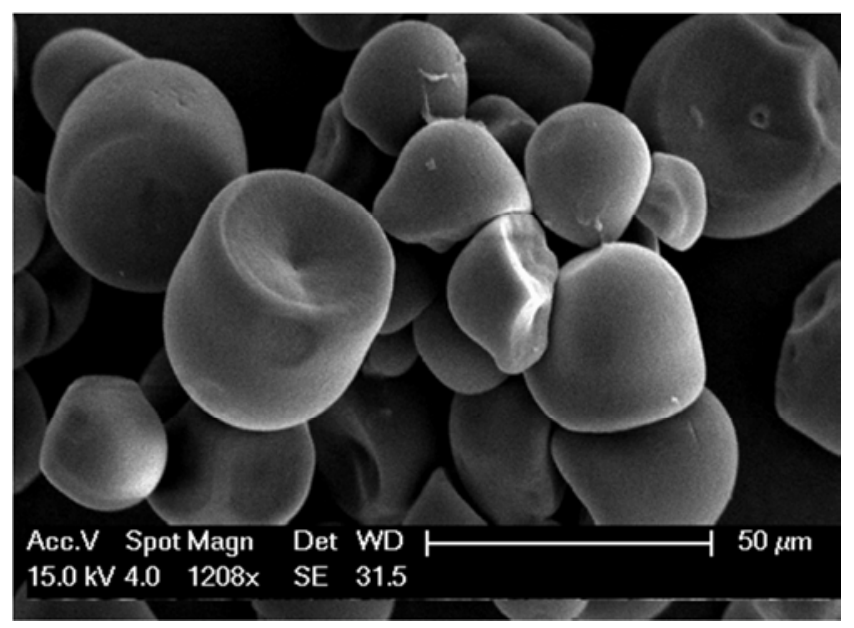

Figure 6. SEM image of starch.

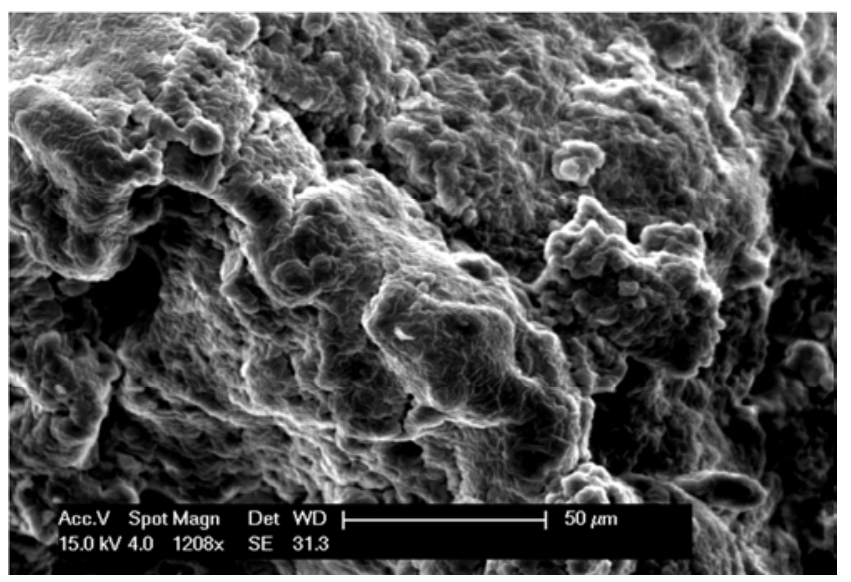

Figure 7. SEM image of starch vernolate.

According to the SEM profiles, the starch granules were mostly converted from their crystalline structure into amorphous state during the dissolution processes, which led to the uniform esterification reaction conducted under conditions involved [37, 49]. The solvent DMSO used as reaction medium during the modification reaction was responsible for disruption the hydrogen bond of starch, sequentially led to the destruction of the crystalline structure of starch granules. This can be the cause for enhanced chemical reagent access to the hydroxyl groups of starch and increase starch reaction with the reagent. The introduction of vernolyl groups disrupt the ordered structure of native starch and hamper the re-association of amylose and amylopectin structures in starch, leading to the change in morphological properties. The morphology of starch vernolates were changed as compared to native cassava starch as a result of esterification. The successful grafting of long chain epoxy fatty acid on to starch using the method mentioned has also been confirmed from the SEM analysis.

\section{Powder X-ray Diffraction}

$X$-ray diffraction has been widely used to detect and characterize the crystalline patterns of starch granules [38]. Starch has a definite crystalline nature and the crystallinity has been assigned to the well-ordered structure of the amylopectin molecules inside the granules [39]. Powder XRD studies provide much of the information about starch granule crystalline properties. Different starches can be classified into A, B or C patterns. $A$ form starch is mainly present in cereal starches, such as maize starch and wheat starch with XRD diffraction peaks at around 15, 17, 18 and $23^{\circ}$. The B form starch is usually available in tuber starch such as potato and this type of starch gives the strongest diffraction peak at $2 \Theta$ of $17^{\circ}$. There were also few small peaks at around $2 \Theta$ values of 20,22 and $24^{\circ}$. The $C$ pattern starch is a mixture of both A and B types, characteristic of smooth seeded pea starch and various bean starches [40].

In starch structure, linear amylose composed of $\alpha-1,4-$ glucopyranose was responsible for the amorphous region, while large amylopectin composed of both $\alpha-1,4$ and $\alpha-1,6-$ glucopyranose contributed to the crystalline region. The Xray powder diffraction pattern obtained for native cassava starch and representative starch vernolate are presented in Figure 8 and Figure 9 below. The native cassava starch powder had crystalline structure, with a strong diffraction pattern. In this study, the diffractogram of native cassava starch exhibited a crystalline pattern, giving three peaks at $2 \Theta$ of $15.34^{\circ}, 17.24^{\circ}, 18.31^{\circ}$ and $23.36^{\circ}$. The occurrence of these peaks confirms that the cassava starch used in our study had an A pattern [41, 42]. This data also agrees with the report by Paulos et al. which shows that cassava starch obtained from cassava tubers collected from three different regions in Ethiopia, namely, Gamo Gofa, Illubabor and Wollega were found to have A-type crystallinity [36].

After esterification, the diffraction pattern showed broad peak, an indication for the amorphous character of the starch vernolate. The highly ordered crystalline structure of cassava starch is related to intra- and intermolecular hydrogen bonds. However, upon esterification, some of the hydroxyl groups on starch backbone were replaced by vernolyl moiety. This has minimized the formation of intermolecular hydrogen bonding and, thereby, disturbing and reducing the orderly crystalline structure of native cassava starch [43, 44]. The relatively higher degree of substitution $(\mathrm{DS}=1.24$ ) obtained 
in our study indicates that much of the hydroxyl groups were substituted by vernolyl group. The samples, as expected, gave an amorphous pattern with a new broad peak appearing around $20^{\circ}$. The presence of this new peak, which was not observed in the diffractogram characteristic of native cassava starch, was another confirmation for the modification of starch by esterification with long chain epoxy fatty acid methyl ester. These broad peaks may have originated from smaller size starch crystals as the esterification reaction continued. Similar results were reported by Zhang et al. [47] and Luo, Z. et al. [51].

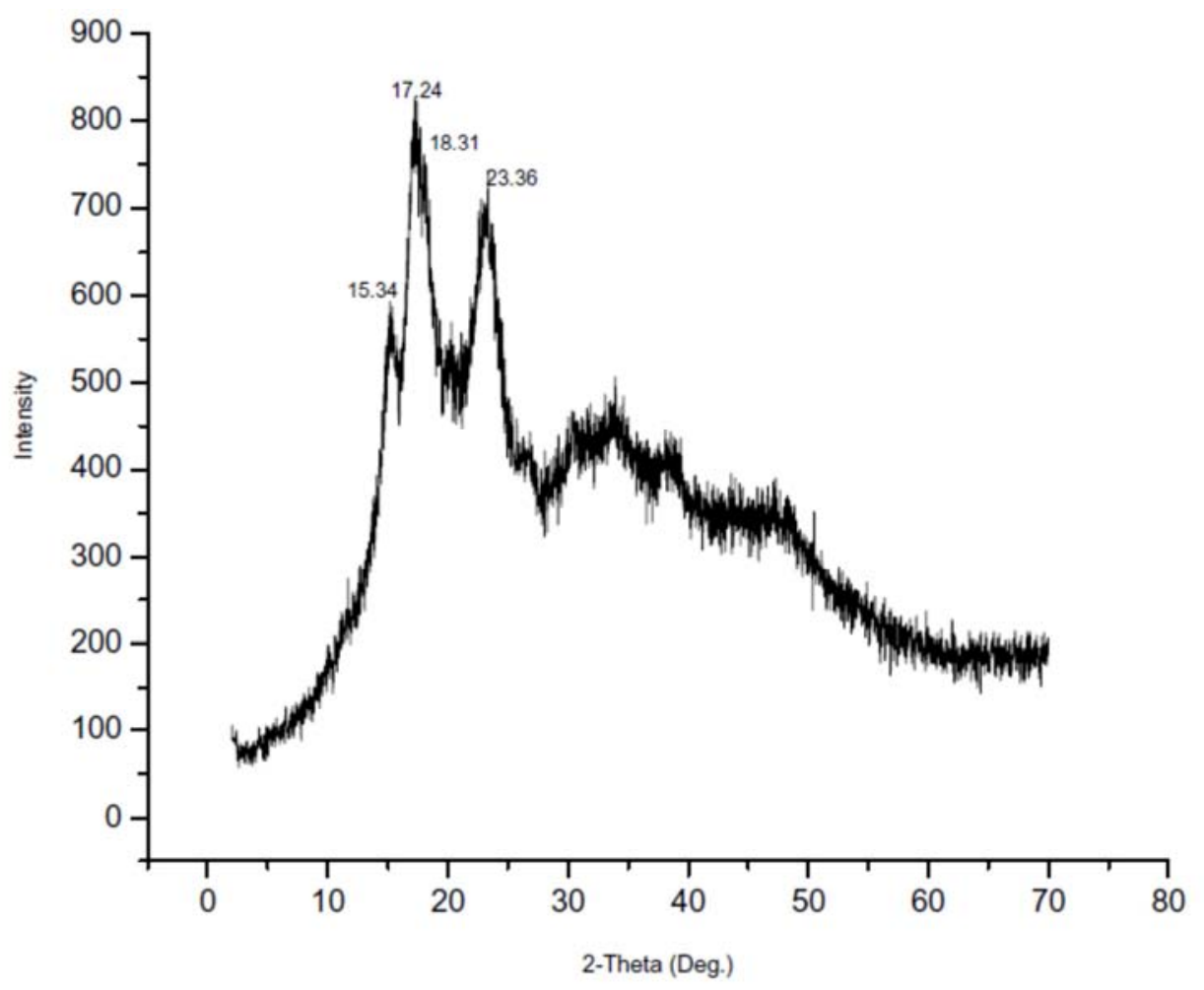

Figure 8. XRD diffractogram of cassava starch.

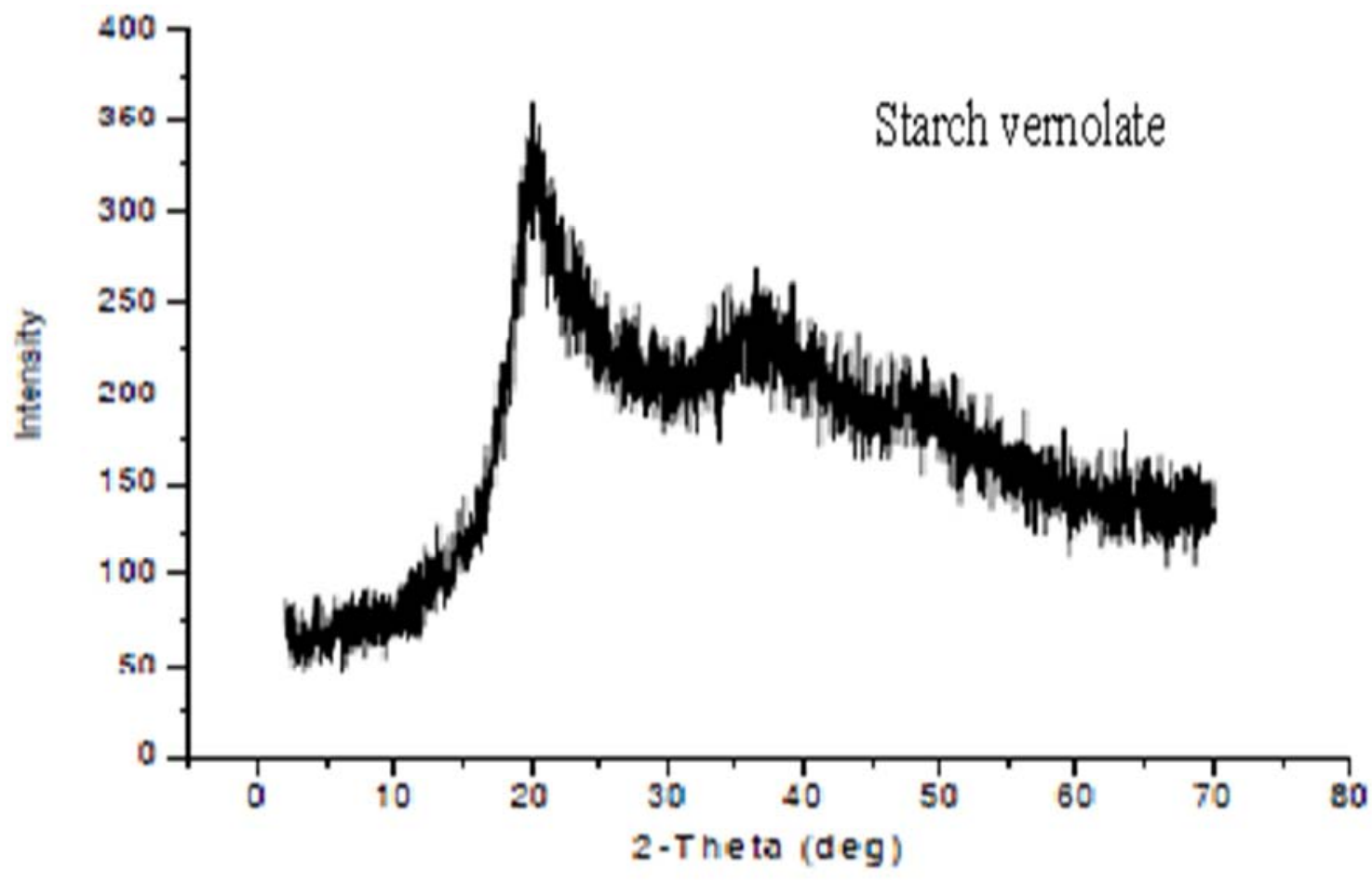

Figure 9. XRD diffractogram of starch vernolate. 


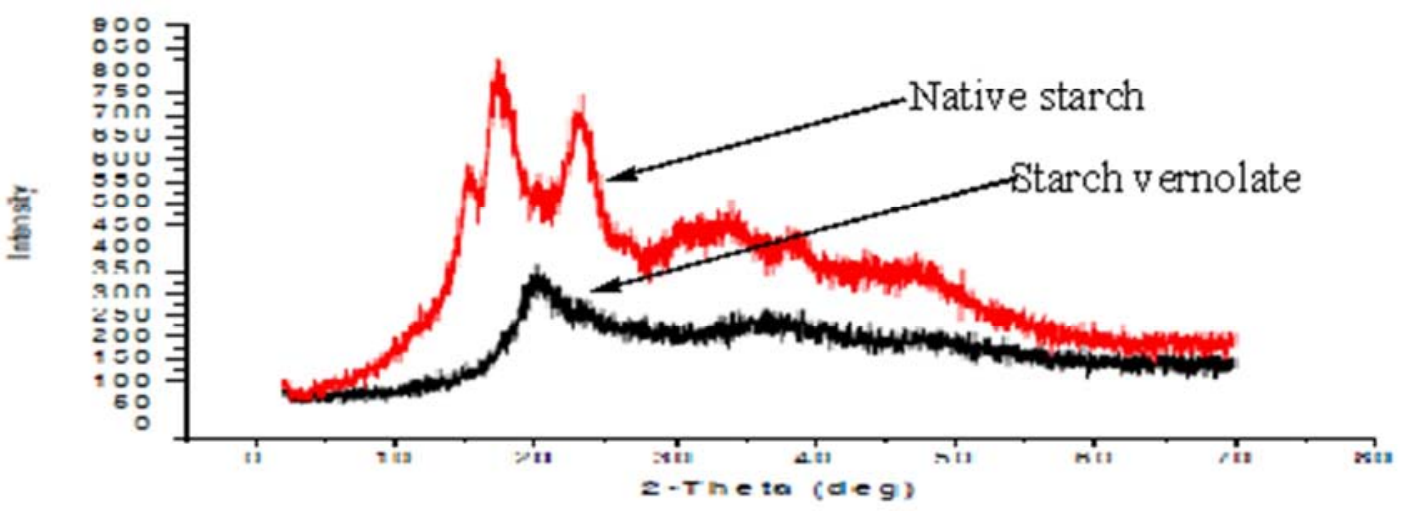

Figure 10. Comparison of XRD diffractogram of starch vernolates with native cassava starch.

\section{Conclusions}

We have synthesized epoxy starch esters (starch vernolates) using DMSO as the solvent for the reaction and basic potassium carbonate as the catalyst. Lower reaction time (12 h) has been achieved while the degree of substitution (DS=1.24) is higher than the previously synthesized starch vernolates using enzymatic catalysis with DS of 0.95 . The resulting epoxy starch ester may be used in the development of biodegradable materials offering an environmentally benign alternative to petroleum based products.

\section{Acknowledgments}

The authors would like to thank the School of Chemistry, University of Nottingham, UK for the analysis of the starch vernolates.

\section{References}

[1] Desalegn, T.; Villar-Garcia, I. J.; Titman, J.; Licence, P.; Diaz, I.; Chebude, Y., Enzymatic synthesis of epoxy fatty acid starch ester in ionic liquid-organic solvent mixture from vernonia oil. Starch/Stärke 2014, 66 (3-4), 385-392.

[2] Meier, M. A. R., Metzger, J. O., Schubert, U. S., Plant oil renewable resources as green alternatives in polymer science. Chem. Soc. Rev. 2007, 36, 1788-1802.

[3] Perdue, R. E., Carlson, K. D., Gilbert, M. G., Vernonia galamensis, potential new crop source of epoxy fatty acid. Econ. Bot. 1986, 40, 54-68.

[4] Grinberg, S., Kolot, V., Mills, D., New chemical derivatives based on Vernonia galamensis oil. Indus. Crop. Prod. 1994, 3, 113-119.

[5] Carlson, K. D., Schneider, W. J., Chang, S. P., Princen, L. H., in: Pryde, E. H., Princen, L. H., Mukherjee, F. (Eds.), New Sources of Fats and Oils, AOCS Monograph 9, American Oil Chemists Society, Champaign, IL, USA 1981, pp. 297-318.

[6] Ayorinde, F. O., Clifton, J., Afolabi, O. A., Shepard, R. L., Rapid transesterification and mass spectrometric approach to seed oil analysis. J. Am. Oil Chem. Soc. 1988, 65, 942-947.

[7] Trumbo, D. L., Rudelich, J. C., Mote, B. E., in: Janick, J. (Ed.), Perspectives on New Crops and New Uses, ASHS Press, Alexandria, VA 1999, pp. 266-271.

[8] Thompson, A. E., Dierig, D. A., Kleiman, R., Characterization of Vernonia galamensis germplasm for seed oil content, fatty acid composition, seed weight, and chromosome number. Indus. Crops Prod. 1994, 2, 299-305.

[9] Ayorinde, F. O., Butler, B. D., Clayton, M. T., Vernonia galamensis: A rich source of epoxy acid. J. Am. Oil Chem. Soc. $1990,67,844-845$.

[10] Tharanathan, R. N., Starch - Value Addition by Modification. Critical Reviews in Food Science and Nutrition, 2005, 45, 371-384.

[11] BeMiller, J. N., Starch modification: challenges and prospects. Starch-Starke 1997, 49: 127-131.

[12] Dzulkefly, K, Koon, S. Y., Kassim, A., Sharif, A., Abdullah, A. H, Chemical Modification of Sago Starch by Solventless Esterification with fatty acid chlorides. The Malaysian Journal of Analytical Sciences, 2007, 11 (2), 395-399.

[13] Mullen, J. W. Pacsu, E., Starch studies: possible industrial utilization of starch esters. Ind. Eng. Chem. 1943, 35, 381-384.

[14] Sagar, A. D., and Merrill, E. W., Properties of fatty-acid esters of starch. J. Appl. Polym. Sci., 1995, 58, 1647.

[15] Junistia, L., Sugih, A. K., Manurung, R., Picchioni, F., Janssen, L., \& Heeres, H. J., Synthesis of higher fatty acid starch esters using vinyl laurate and stearate as reactants. Starch/Stärke 2008, 60, 667-675.

[16] Aburto, J., Alric, I., Borredon, E. Preparation of long-chain esters of starch using fatty acid chlorides in the absence of an organic solvent. Starch/Stärke 1999, 51, 132-135.

[17] Aburto, J., Alric, I., \& Borredon, E. Organic solvent-free transesterification of various starches with lauric acid methyl ester and triacyl glycerides. Starch/Stärke, 2005. 57, 145-152.

[18] Rajan, A., Prasad, V. S., Abraham, T. E., Enzymatic esterification of starch using recovered coconut oil. International Journal of Biological Macromolecules 2006,39, 265-272. 
[19] Elhilo, E. B., Melissa, A. A., Ayorinde, F. O., Synthesis of cis-12,13-epoxy-cis-9-octadecenol and 12(13)-hydroxy-cis-9octadecenol from Vernonia oil using lithium aluminum hydride. J. Am. Oil Chem. Soc. 2000, 77, 873-878.

[20] Mathew, S., Abraham, T. E., Physico-chemical characterization of starch ferulates of different degrees of substitution. Food Chemistry 2007, 105, 579-589.

[21] Garg, S., Jana, A. K., Characterization ands evaluation of acylated starch with different acyl groups and degrees of substitution. Carbohydrate Polymers 2011, 83, 1623-1630.

[22] Goheen, S. M., Wool, R. P., Degradation of polyethylene starch blends in soil. J. Appl. Polym. Sci.1991, 42, 2691-2701.

[23] Kapusniak, J., Siemion, P., Thermal reactions of starch with long-chain unsaturated fatty acids part 2. Linoleic acid. Journal of Food Engineering 2007, 78, 323-332.

[24] Aburto J, Alric I, Thiebaud S. Synthesis, characterization, and biodegradability of fatty-acid esters of amylose and starch. $J$ Appl Polym Sci, 1999, 74: 1440-1451.

[25] Zhang, L., Xie, W., Zhao, X., Liu, Y., Gao, W., Study on the morphology, crystalline structure and thermal properties of yellow ginger starch acetates with different degrees of substitution. Thermochimica Acta 2009, 495, 57-62.

[26] Fang, J. M., Fowler, P. A., Tomkinso, J., \& Hill, C. A. S. The preparation and characterization of a series of chemically modified potato starches. Carbohydrate Polymers 2002, 47, 245-252.

[27] Horchani, H., Chaabouni, M., Gargouri, Y., Sayari, A., Solvent free lipase-catalyzed synthesis of long-chain starch esters using microwave heating: Optimization by response surface methodology. Carbohydrate Polymers 2010, 79, 466474.

[28] Jyothi, A. N., Sajeev, M. S., Parvathy, P. C., Sreekumar, J., Optimization of synthesis and characterization of cassava starch-graft-poly(acrylonitrile) using response surface methodology. Journal of Applied Polymer Science, 2011, 122, $1546-1555$.

[29] Rodriguez, A., Sain, M., Jeng, R., Thermal characterization of starch-based polymers produced by Ophiostoma spp. J Therm Anal Calorim 2009, 98, 317-323.

[30] Sagar A. D, Merrill E. W., Properties of fatty-acid ester of starch. J Appl Polym Sci, 1995, 58, 1647-1656.

[31] Shogren, R. L., Preparation, thermal properties, and extrusion of high-amylose starch acetates. Carbohydr Polym, 1996, 29, $57-62$.

[32] Aburto, J., Alric, I., Thiebaud, S., Synthesis, characterization, and biodegradability of fatty-acid esters of amylose and starch J. Appl. Polym. Sci., 1999, 74, 1440-1451.

[33] Xie, W., Zhang, Y., Liu, Y., Homogenous carboxymethylation of starch using 1-butyl-3-methylimdazolium chloride ionic liquid medium as solvent. Carbohydrate Polymers 2011,85, 792-797.

[34] Muljana, H., Picchioni, F., Heeres, H. J., Janssen P. B. M., Process-product studies on starch acetylation reactions in pressurized carbon dioxide. Starch/Stärke 2010, 62, 566-576.
[35] Garcia, V., Colonna, P., Bouchet, B., and Gallant, D. J., Structural changes of cassava starch granules after heating at intermediate water contents. Starch/Stärke 1997, 49 171-179.

[36] Paulos, G., Endale, A., Bultosa, G., and Gebre-Mariam, T., Isolation and Physicochemical Characterization of Cassava Starches Obtained from Different Regions of Ethiopia. Ethiop Pharm J 2009, 27, 42-54.

[37] Xie, W., Shao, L., Liu, Y., Synthesis of starch esters in ionic liquids. J. Appl. Polym. Sci. 2010, 116, 218-224.

[38] Hoover, R., Composition, molecular structure, and physicochemical properties of tuber and root starches: A review. Carbohydrate Polymers, 2001, 45: 253-267.

[39] Moorthy, S. N., Physicochemical and Functional Properties of Tropical tuber starches: A Review. Starch/Stärke 2002, 54, 559-592.

[40] Shujun, W., Jinglin, Y., Wenyuan, G., Use of X-Ray Diffractometry (XRD) in the identifiocation of Fritillaria According to Geographical origin. Am. J. Biochem. \& Biotechnol. 2005, 1 (4), 199-203.

[41] Defloor, I., Dehing, I., Delcour, J. A., Physico-chemical properties of cassava starch. Starch/Stärke 1998, 50(2-3), 5864.

[42] Kuo, W. Y., Lai, H. M., Changes of property and morphology of cationic corn starches. Carbohydrate Polymers, 2007, 69(3), $544-553$.

[43] Xu, Y., Miladinov, V., and Hanna, M. A. Synthesis and Characterization of starch acetates with high substitution. Cereal Chem. 2004, 81, 735-740

[44] Xu, W., Wenyuan, G., Liming, Z., Peigen, X., Liping, Y., Yi, L., Kefeng, L., Weiguang, X., Study on the morphology, crystalline structure and thermal properties of yam starch acetates with different degrees of substitution. Sci China Ser B-Chem. 2008, 51, 859-865.

[45] Zhang, L., Xie, W., Zhao, X., Liu, Y., Gao, W., Study on the morphology, crystalline structure and thermal properties of yellow ginger starch acetates with different degrees of substitution. Thermochimica Acta 2009, 495 57-62.

[46] Carvalho, J., Goncalves, C., Gil, A. M., Gama, F. M., Production and characterization of a new dextrin based hydrogel. European Polymer Journal 2007, 43, 3050-3059.

[47] Killinger, W. E., Murray, D., Hatfield, G. R., Hassler, T., Determination of the Degree of Cationicity in Cationic Starches by Solid-state 13C NMR Spectroscopy. Starch/Stärke 1995, 47, 311-314.

[48] Li, J., Zhang, L., Peng, F., Bian, J., Yuan, T., Xu, F., and Sun R., Microwave-Assisted Solvent-Free Acetylation of Cellulose with Acetic Anhydride in the Presence of Iodine as a Catalyst. Molecules 2009, 14, 3551-3566.

[49] Luo, Z., and Zhou, Z., Homogenous synthesis and characterization of starch acetates in ionic liquid without catalysis. Starch/Stärke 2012, 64, 37-44.

[50] Desalegn, T.; Villar-Garcia, I. J.; Titman, J.; Licence, P.; Diaz, I.; Chebude, Y., Synthesis of Starch Vernolate in 1-Butyl-3methylimidazolium Chloride Ionic Liquid. Starch/Stärke 2015, 67, 200-203. 